\title{
BMJ Open Funding for cerebral palsy research in Australia, 2000-2015: an observational study
}

\author{
D L Herbert, ${ }^{1}$ A G Barnett, ${ }^{2}$ R White, ${ }^{3}$ I Novak, ${ }^{1}$ N Badawi ${ }^{1,4}$
}

To cite: Herbert DL, Barnett AG, White R, et al. Funding for cerebral palsy research in Australia, 20002015: an observational study. BMJ Open 2016;6:e012924. doi:10.1136/bmjopen-2016012924

- Prepublication history for this paper is available online. To view these files please visit the journal online (http://dx.doi.org/10.1136/ bmjopen-2016-012924).

Received 3 June 2016 Revised 12 September 2016 Accepted 5 October 2016

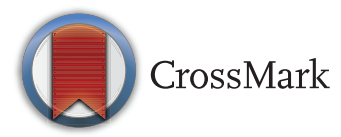

${ }^{1}$ Cerebral Palsy Alliance Research Institute, The University of Sydney, Sydney, New South Wales, Australia ${ }^{2}$ School of Public Health \& Social Work, Queensland University of Technology, Brisbane, Queensland, Australia

${ }^{3}$ Cerebral Palsy Alliance, Sydney, New South Wales, Australia

${ }^{4}$ Grace Centre for Newborn Care, Children's Hospital at Westmead, Sydney, New South Wales, Australia

Correspondence to Dr Danielle Herbert; danielleherbert11@gmail.com

\section{ABSTRACT}

Objectives: To examine the funding for cerebral palsy (CP) research in Australia, as compared with the National Institutes of Health $(\mathrm{NIH})$.

Design: Observational study.

Setting: For Australia, philanthropic funding from Cerebral Palsy Alliance Research Foundation (CPARF) (2005-2015) was compared with National Health and Medical Research Council (NHMRC, 2000-2015) and Australian Research Council (ARC, 2004-2015) and CPARF and NHMRC funding were compared with NIH funding (USA).

Participants: Cerebral Palsy researchers funded by CPARF, NHMRC or NIH.

Results: Over 10 years, total CPARF philanthropic funding was $\$ 21.9$ million, including people, infrastructure, strategic and project support. As competitive grants, CPARF funded $\$ 11.1$ million, NHMRC funded $\$ 53.5$ million and Australian Research Council funded \$1.5 million. CPARF, NHMRC and NIH funding has increased in real terms, but only the NIH statistically significantly increased in real terms (mean annual increase US $\$ 4.9$ million per year, $95 \% \mathrm{Cl} 3.6$ to $6.2, p<0.001)$. The NHMRC budget allocated to $\mathrm{CP}$ research remained steady over time at $0.5 \%$. A network analysis indicated the relatively small number of $\mathrm{CP}$ researchers in Australia is mostly connected through CPARF or NHMRC funding.

Conclusions: Funding for $\mathrm{CP}$ research from the Australian government schemes has stabilised and CP researchers rely on philanthropic funding to fill this gap. In comparison, the NIH is funding a larger number of $\mathrm{CP}$ researchers and their funding pattern is consistently increasing.

\section{INTRODUCTION}

Medical research delivers large health, social and economic benefits. ${ }^{1}$ As countries continue to invest in health, global investment in medical research continues to climb, especially in high-income countries. ${ }^{2}$ Disproportionate amounts of research funding are spent on: (1) conditions with relevance in high-income countries even though the disease burden is greater in low-income countries ${ }^{2}$ and

\section{Strengths and limitations of this study}

- This study examines the current state of philanthropic and competitive funding for cerebral palsy (CP) research in Australia, and the direction that competitive funding for CP research is moving in relation to National Institutes of Health (NIH) funding in the USA.

- In Australia, the analysis of funding from National Health and Medical Research Council (NHMRC) and the Australian Research Council (ARC) is limited by the public availability of summary spreadsheets and final project summaries and the specific ARC exclusion of medical and clinical research.

- The findings are an underestimate of CP funding as the search for grants was based on strict keyword searches, and the comparison between Australia and the USA is limited to competitive grants (NHMRC and NIH). The analysis is also limited due to the exclusion of other philanthropic or charitable organisations in Australia and the USA.

(2) prevalent and costly public health problems secure government funding priorities in preference to rarer diseases. Philanthropic funding for global research is crucial, ${ }^{3}$ and the important role of research patient organisations has been recognised for brain disorders in Canada ${ }^{4}$ and rare diseases in Australia. ${ }^{5}$ In the USA, the independent organisation Patient-Centered Outcomes Research Institute (PCORI) provides funding for patient-focused research that encourage collaborations across sectors to provide benefit directly to patients, including new projects in 2016 for people and families living with $\mathrm{CP}$.

$\mathrm{CP}$ is the most common childhood physical disability with a prevalence of 3.1 per 1000 births in four areas of the USA, ${ }^{6}$ compared with 2.1 per 1000 live births in Australia. ${ }^{7}$ In the last 10 years, the Australian rate has decreased from 1-in-526 births to 1-in-625 births, alongside reductions in co-occurring 
epilepsy (20\% reduction), intellectual disability (17\%) and wheelchair use $(15 \%) .{ }^{8}$ These reductions are evidence of the cumulative translation of research findings from projects that started with CP funding.

Additional research impacts include reducing the collective economic costs of $\mathrm{CP}$ on the Australian community, estimated in 2007 to be almost $\$ 4$ billion annually. ${ }^{9}$ In Australia, people living with $\mathrm{CP}$ and their families have clearly articulated prevention and cure of CP as their highest priorities for future research as identified by a Delphi study. ${ }^{10}$ Yet the public and health professionals' perception regarding CP has historically been a disability that cannot be prevented or cured, and so the research has focused on interventions aimed at improving quality of life. A key role for CP researchers and CP advocates worldwide is to challenge these public perceptions. ${ }^{8}$ Prevention and cure may include a reduction in $\mathrm{CP}$ severity where people are mobile and do not require a wheelchair or no longer have epilepsy. ${ }^{11}$

The aim of this study is to examine the current state of philanthropic and competitive funding for CP research in Australia, and the direction that competitive funding for CP research is moving in relation to the USA. In the past decade, the focus of Australian CP research has expanded from interventions and therapies, to prevention and cure of CP. In comparison with the NIH funding for CP research, ${ }^{12}{ }^{13}$ Australia has a smaller yet growing community of $\mathrm{CP}$ researchers seeking funding. This study will examine the funding for CP research in Australia from the single philanthropic funding body specifically for $\mathrm{CP}$ research and the major competitive funding schemes from the government. It will examine: (1) whether CP funding is increasing in real terms; (2) whether CP funding in Australia is increasing compared with the NIH and (3) the Australian community of CP researchers and how these networks have interacted to successfully obtain funding.

\section{METHOD}

To obtain a complete picture of competitive and philanthropic funding of CP research in Australia, information was sought from Cerebral Palsy Alliance (CPA), NHMRC and ARC.

\section{Funding bodies}

The CPA is a not-for-profit organisation established by parents that provides services to clients with CP and their families living in the Australian state of New South Wales and Australian Capital Territory, and was formerly known as The Spastic Centre of New South Wales as established in $1945 .^{14}$ The Cerebral Palsy Alliance Research Foundation (CPARF) was established in 2005 from ongoing fund raising and donor support, and from 2011 receives donations from the annual STEPtember global charity event. CPARF established the Research Institute in 2005 to be dedicated to CP research, awarded the first grants in 2006, hosted the International CP
Conference in 2009 and subsequently funded Australia's first Professorial Chair of Cerebral Palsy as a university appointment. $^{15}$

The Australian Government provides competitive grant funding through: (1) NHMRC as the major funding body for health and medical research; and (2) ARC funds research and innovation, including industry partnerships, specifically excluding medical, clinical or dental research. In the past decade, and relative to NHMRC and ARC, CPARF is the new funding scheme that is specifically for CP research.

\section{Funding type}

Cerebral Palsy Alliance Research Foundation (CPARF)

Total CPARF funding was categorised as: (1) people and infrastructure; (2) strategic grants to pursue prevention and cure and (3) competitive grants. ${ }^{15}$ The CPARF competitive grants programme is administered through a formal application process including external peer review. The research priorities for the programme are prevention and cure of CP, and novel interventions. From 2006 to 2015, CPARF provided two competitive funding schemes: People (ie, Career Development) and Project grants. People grants cofunded with the NHMRC $(n=9)$ were excluded from the CPARF analysis to avoid double counting; these nine grants are included with the NHMRC.

\section{National Health and Medical Research Council (NHMRC)}

NHMRC data were grouped into Centre, People or Project grants. Centre grants included: Centre for Research Excellence, Centre for Clinical Excellence, Development and Programme. People grants included: Fellowships (Early Career, Career Development, Research, Translating Research into Practice) and Postgraduate Scholarships. Project grants included Project and Partnership schemes. In 2015, two sources of NHMRC data were used: spreadsheet of funding expenditure per year (2000-2015) and final reports for People or Project grants (2004-2012). ${ }^{16} 17$

NHMRC inclusion/exclusion criteria: We extracted CP-related grants from the complete list of NHMRC grants by searching for the keywords 'cerebral' and 'palsy', or the phrase 'neonatal encephalopathy' in the final reports. The absence of these keywords/phrase in the NHMRC data excluded grants that may be known to benefit $\mathrm{CP}$ research, resulting in an underestimate of total CP funding. For the 2015 NHMRC data, only the lead researcher was listed in the public domain and no data were available on the funding breakdown by year, so we assumed the total income was spread equally over the (future) funded years.

NHMRC final reports were available for 2004-2012 only; the datasets were publicly accessible from the NHMRC website in 2015. The search of the final reports uncovered projects that were only partly related to $\mathrm{CP}$, for example, CP was referred to as a potential consequence but was not the main aim; these projects were 
excluded from the analysis. For grants that were not solely dedicated to $\mathrm{CP}$ a fraction of funding was used, for example, CP was one of four conditions mentioned in the final report, the total funding amount was divided by four and that quarter amount was included in the analysis. These were crude adjustments, but avoided overestimating the total funding for $\mathrm{CP}$ research. Clinical trials that were not solely focused on CP, or may have translated to $\mathrm{CP}$ in the future, were excluded. Additional NHMRC spreadsheets were searched for funding allocations by health condition or disease; this data is a combination of information provided by the researchers in their original applications and subjective determinations by internal NHMRC processes. ${ }^{16}$

\section{Australian Research Council (ARC)}

ARC competitive grant schemes for People (Future Fellowship) and Projects (Discovery and Linkage) specifically exclude medical, clinical and dental research that examines the understanding or treatment of a health condition or disease. ${ }^{18}$ ARC funded projects from 2004 to 2015 were searched for the keywords 'cerebral' and 'palsy'; the medical phrase 'neonatal encephalopathy' was not used, given the ARC exclusion of medical research. Grants using the keyword 'disability', and not specifically 'cerebral palsy' were excluded.

\section{National Institutes of Health (NIH)}

NIH summary data were provided by $\mathrm{Wu}$ et $a l^{12}$ on CP funding among all NIH-funded studies from 2001 to 2012 in the USA. Wu et $a l^{12}$ searched the NIH databases Research Portfolio Online Reporting Tools Expenditures and Results, and Research, Condition, and Disease Categorization for the key phrase 'cerebral palsy', and summarised the data as basic or clinical research. ${ }^{12}$ The NIH funding is shown in this study as the combined total amount, and in terms of award year rather than expenditure year.

\section{Funding trends}

Plots for funding trends are expenditure over time. There are two ways of displaying funding over time: (1) by the year the grant was awarded and (2) by the year of expenditure. Our preference is to show the results by expenditure year as this is a better reflection of overall research activity. For the 2015 NHMRC grants where the annual expenditure was unavailable, the total amount was spread evenly over the years of the project. For example, a project with a total budget of $\$ 300000$ running from 2015 to 2017 would have $\$ 100000$ in each year. Annual totals were used to show the overall levels of expected research activity over time.

Annual funding figures were adjusted for inflation using the Australian consumer price index (US index for NIH data), which reflects the historic change in purchasing power over time. ${ }^{19}$ We compared the similarity in trends over time using time series plots, calculated the Pearson correlation between the three funding agencies and used linear regression to look for a statistical increase in funding over time. All analyses were completed using R V.3.2.2 (R Core Team. R: A Language and Environment for Statistical Computing. Vienna, Austria: R Foundation for Statistical Computing, 2015. https://www.R-project.org).

\section{Network analysis}

The network analysis examined the links between researchers who won funding from CPARF or NHMRC. If two researchers were investigators on the same grant they are linked in the network diagram. Researchers were anonymised by number ranking according to their overall income from the respective funding body, with the 'number 1' assigned to the highest funding earner. The 'igraph' library in $\mathrm{R}$ was used to produce networks for CPA or NHMRC funding.

\section{RESULTS \\ CPARF funding}

The total CPARF philanthropic funding for CP research in Australia (2005-2015, figure 1) is \$21 905997 and allocated as: (1) \$7073638 to support people and infrastructure forming the Cerebral Palsy Alliance Research Institute; (2) \$3680375 to Strategic Grants and (3) \$11 151984 to Competitive Grants. Among the Strategic Grants, the key funding allocations included the: 2009 International CP Conference held in Sydney, Australia; establishment of the CP Registers, including database development and people support and the strategic focus from 2015 on stem cells and genomics for the future prevention and cure of CP. Among the Competitive Grants, \$686084 was contributed directly to the NHMRC to support cofunded NHMRC doctoral scholarships $(n=7)$ and fellowships $(n=2,2014-2015)$ to build capacity among CP researchers.

\section{NHMRC funding by health condition}

From 2000 to 2014, NHMRC funding for CP research increased in real terms (figure 2). From the NHMRC database for disease and health issues, ${ }^{16} \mathrm{CP}$ funding is comparable with other related health conditions: (1) CP and autism are included under developmental disorders and disability; (2) CP and Parkinson's disease are included under nervous system (Neuroscience) disorders; and (3) cystic fibrosis and childhood diabetes are comparable with $\mathrm{CP}$ as they are also a lifelong condition diagnosed in childhood.

In 2012, the NHMRC funding for all people living with the respective condition was: AU $\$ 2.2$ million for CP; AU \$4.3 million for autism; AU\$3.3 million for cystic fibrosis; AU $\$ 7.7$ million for Parkinson's disease and AU $\$ 6.3$ million for childhood diabetes. ${ }^{16}$ For an individual person living with the respective condition, this equated to NHMRC funding of: $\mathrm{AU} \$ 64$ for $\mathrm{CP} ; \mathrm{AU} \$ 67$ for autism; AU $\$ 1046$ for cystic fibrosis; AU $\$ 154$ for Parkinson's disease and AU $\$ 1097$ for childhood 


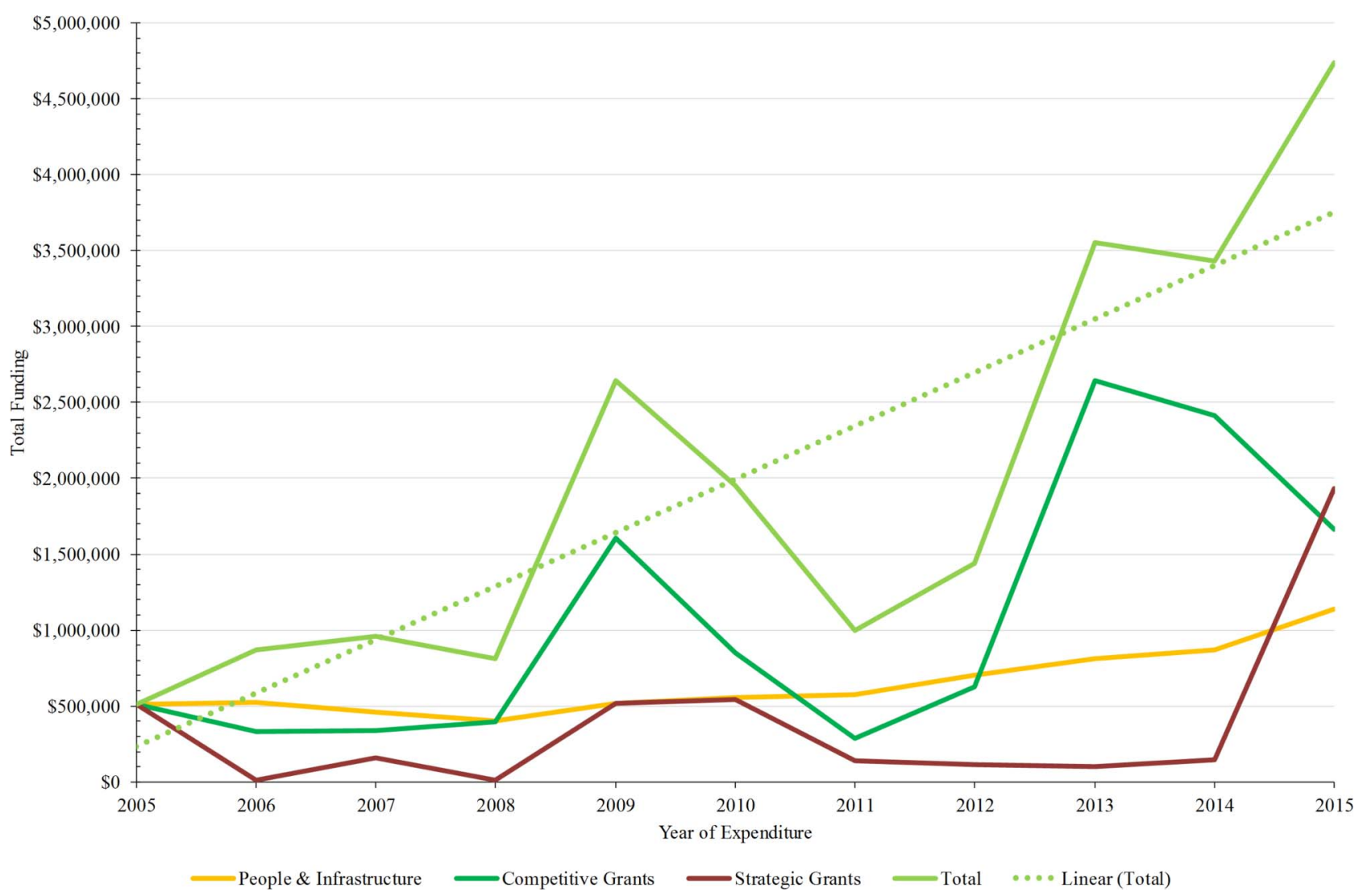

Figure 1 Cerebral Palsy Alliance Research Foundation total funding, 2005-2015; linear trend for total expenditure shown as a straight, dotted line. The funding amounts are in dollar values for the year the total funding was awarded.

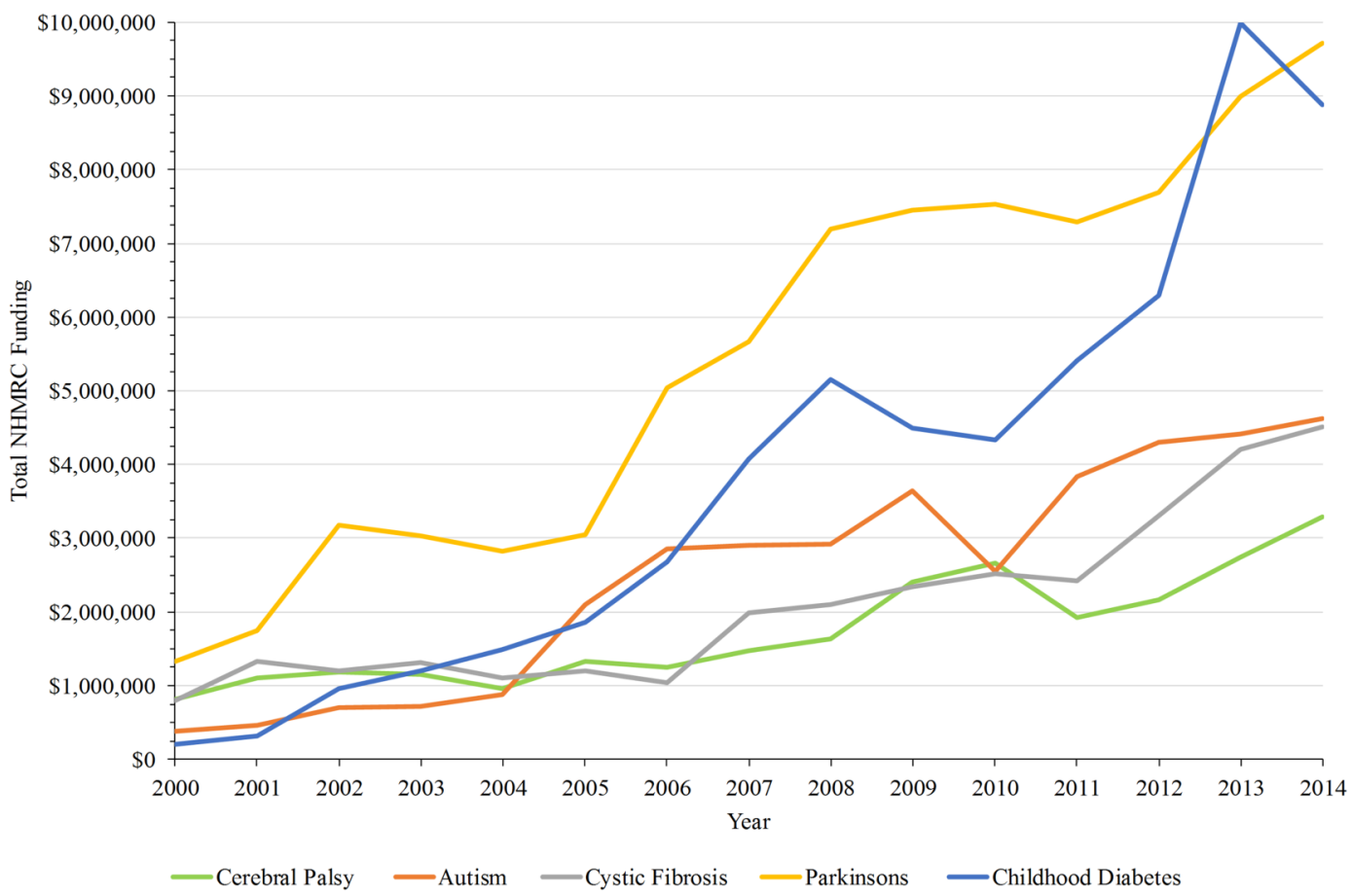

Figure 2 National Health and Medical Research Council Funding by Health Condition: cerebral palsy and comparable childhood or neurological conditions. The funding amounts are in dollar values for the year the total funding was awarded. 
diabetes. In comparison, NIH funding in 2014 for an individual person living with the condition equated to US $\$ 27$ for CP, US\$53 for autism and US\$2566 for cystic fibrosis. ${ }^{13}$

\section{Competitive grants}

The funding for CP research in Australia (2000-2015) is compared between the philanthropic CPARF, and the major government funding bodies NHMRC and ARC (figure 3). From 2005 to 2015, the CPARF funded 102 grants: People $(n=27)$ and Project $(n=75)$. The total amount spent on competitive grants was $\$ 10645900$ (in 2015 dollars after adjustment for inflation is \$11 209 557). There was relatively large variability in funding over time. In 2011 and 2012, the funding levels dipped, but increased greatly from 2013 to 2015 . The CPARF average total amount invested per year was $\$ 878094$.

From 2000 to 2015, the NHMRC funded 125 grants for $\mathrm{CP}$ research, as identified from the spreadsheets $(n=105)$, final reports $(n=2)$ or both $(n=18)$; and summarised into People $(n=51)$, Project $(n=67)$ or Centre $(n=7)$. The total NHMRC funding spent on CP research was \$53 533966 (in 2015 dollars after adjustment for inflation is $\$ 63035914)$. Six ARC grants were related to CP research and included the areas of citizenship and independent living: People $(n=1)$ and Project $(n=5)$. The ARC total amount spent on CP research was \$1 541956 (in 2015 dollars after adjustment for inflation is $\$ 1706$ 647). Due to the low number of ARC grants for $\mathrm{CP}$ research, the analysis is limited for any comparisons with CPARF or NHMRC.
NHMRC and CPARF sources of competitive funding show a general upward trend in funding with some boom years (figure 3 ). The large correlation between the NHMRC and CPARF $(\mathrm{r}=0.84, \mathrm{p}=0.002)$ is partly driven by the steady rise over time for both funding agencies. For comparison purposes, figure 3 includes the total funding awarded from the CPARF (total from figure 1) and the total NHMRC funding for $\mathrm{CP}$ as the target health condition nominated by $\mathrm{CP}$ researchers in their original applications (total from figure 2, \$26 million from 2000 to 2015). This analysis identified far more CP funding by the NHMRC (\$53.5 million) compared with the data set prepared by the NHMRC based specifically on health conditions nominated by the researchers; a difference of over $\$ 27$ million in identified grants.

\section{Comparison with NIH}

The NIH funding is shown in terms of award year rather than expenditure year as provided by $\mathrm{Wu}$ et al. ${ }^{12}$ Funding for CP in the USA has greatly increased in real terms (figure 4). The mean increase in funding per year was: \$105000 for NHMRC funding, \$184000 for CPARF funding and US $\$ \$ 4.9$ million per year for NIH funding. The increase in funding over time was statistically significant for the NIH (mean $\$ 4.9$ million, $95 \%$ CI $3.6 \mathrm{M}$ to $6.2 \mathrm{M}, \mathrm{p}<0.001$ ), but not for the NHMRC (mean $\$ 104 \mathrm{~K}$, $95 \% \mathrm{CI}-77 \mathrm{~K}$ to $287 \mathrm{~K}, \mathrm{p}=0.2$ ) and CPARF (mean $\$ 184 \mathrm{~K}$, $95 \% \mathrm{CI}-10 \mathrm{~K}$ to $379 \mathrm{~K}, \mathrm{p}=0.06$ ).

In the USA, funding for $\mathrm{CP}$ has also increased in terms of the per cent overall share of the NIH budget.

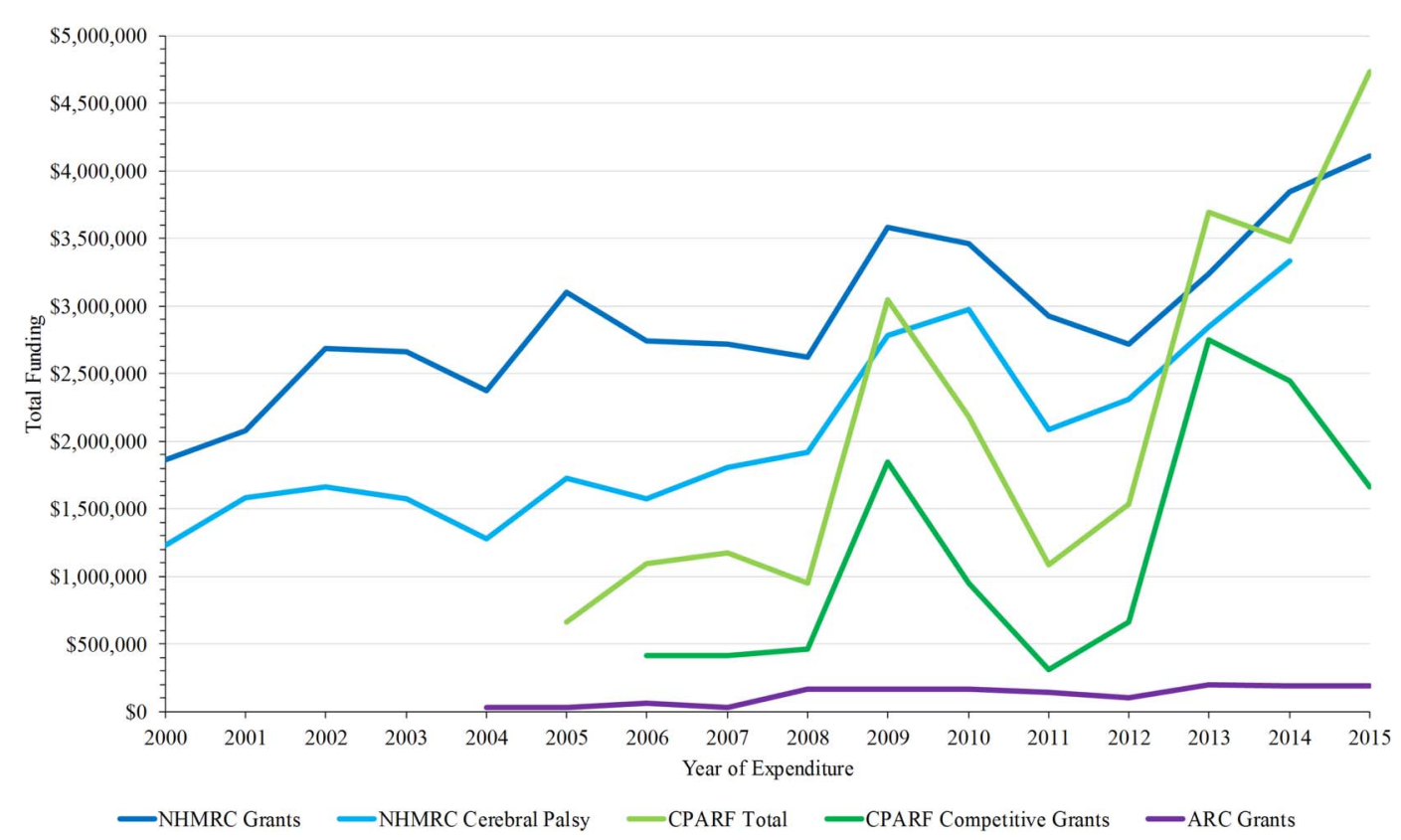

Figure 3 Total funding for cerebral palsy research in Australia (2000-2015): Cerebral Palsy Alliance Research Foundation (CPARF, competitive and total), National Health and Medical Research Council (original applications and categorised by cerebral palsy) and Australian Research Council (original applications). The funding amounts are in 2015 dollars as adjusted for inflation for the year of expenditure of funding. 
Figure 4 Total funding for cerebral palsy research by National Health and Medical Research Council (NHMRC, Australia), Cerebral Palsy Alliance Research Foundation (CPARF, Australia) and National Institutes of Health (NIH, USA): (A) total dollars awarded per year and $(B)$ percentage of total funding budget. Linear trend shown as straight line; adjusted for inflation. $\mathrm{NIH}$ data provided by Wu et al. ${ }^{12}$ The funding amounts are in 2015 dollars as adjusted for inflation for the year of expenditure of funding for NHMRC and CPARF, and year awarded for $\mathrm{NIH}$. (A) Total funding \$. (B) Per cent of total budget

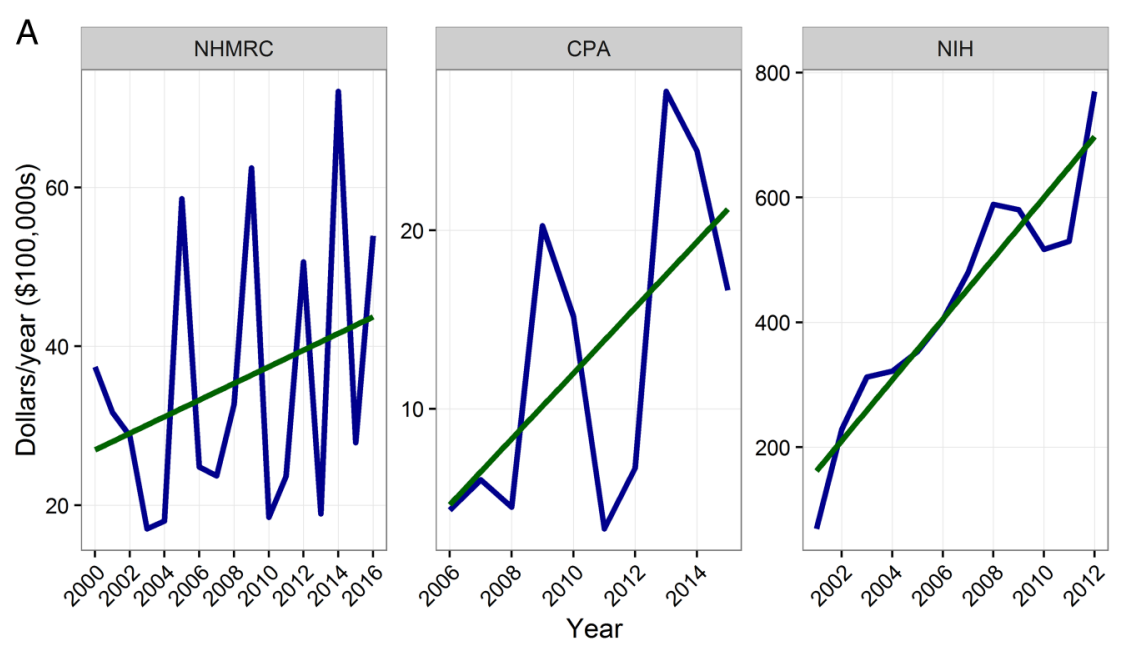

B

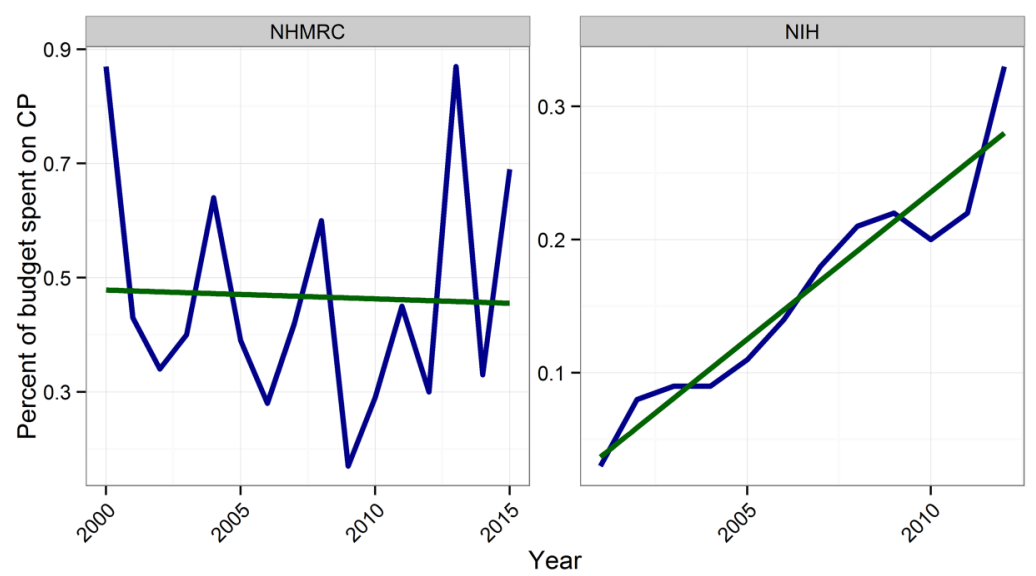

The increasing per cent share of NIH budget allocated to CP research over time was statistically significant (mean $0.02 \%, 95 \%$ CI $0.02 \%$ to $0.03 \%, \mathrm{p}<0.001$ ), whereas the NHMRC change over time was close to zero (mean $-0.002 \%, 95 \%$ CI $-0.03 \%$ to $0.02 \%, \mathrm{p}=0.9$ ). The average annual per cent of the NHMRC budget allocated to CP research from 2000 to 2015 remained relatively flat at $0.5 \%$.

\section{Network analysis}

The CPARF and NHMRC network analysis (figure 5) shows a number of small groups of 3-6 researchers, based on individual grants. The largest CPARF network is three groups joined through a single high-earning researcher (number 14). The largest NHMRC network is 18 researchers joined by four key linking researchers (numbers 1, 2, 6 and 17). The network analysis indicates most CP researchers are connected through collaborations for funding. CPARF connections are broader compared with the tighter established teams obtaining NHMRC funding. Further, there are more 'islands' among the CPARF network indicating the new researchers entering the CP research field, as compared with the fewer 'islands' in the NHMRC network. Two 'islands' in the network analysis of NHMRC funding include two relatively successful researchers (numbers 8 and 9 winning four and eight grants, respectively) who are at the centre of small networks that are not linked to the main network.

\section{DISCUSSION}

In Australia, funding for CP research from the major competitive grant schemes has stabilised in the last decade. Historically, there have been irregular patterns of funding and as a consequence there is a heavy reliance on philanthropic donations to fill the gap. As there is a relatively small number of $\mathrm{CP}$ researchers in Australia, and because NHMRC success rates are low (currently under 15\%), the annual funding awarded is sporadic. Researchers try 1 year and if they miss out, they need to resubmit the following year. ${ }^{21}{ }^{22}$ This results in irregular funding patterns for NHMRC money and subsequent impacts on maintaining research momentum. In the USA, the NIH is funding a larger number of $\mathrm{CP}$ researchers and their funding pattern is consistently increasing. CP needs to be a focus for the NHMRC to provide consistent funding to achieve the priorities highlighted by Australian families living with CP. $^{10}$

It is intriguing how the ups and downs in NHMRC funding are mirrored by the CPARF (with a strong correlation between the two amounts). A possible 
Figure 5 Network diagram of anonymised cerebral palsy researchers by funding agency in Australia. Researchers are numbered according to their overall income with 1 the highest earner. (A) Funded by Cerebral Palsy Alliance Research

Foundation. Lowest earner: 185. Largest network through: 14 .

(B) Funded by National Health and Medical Research Council. Lowest earner: 169. Largest networks through: 1, 2, 6 and 17.
A

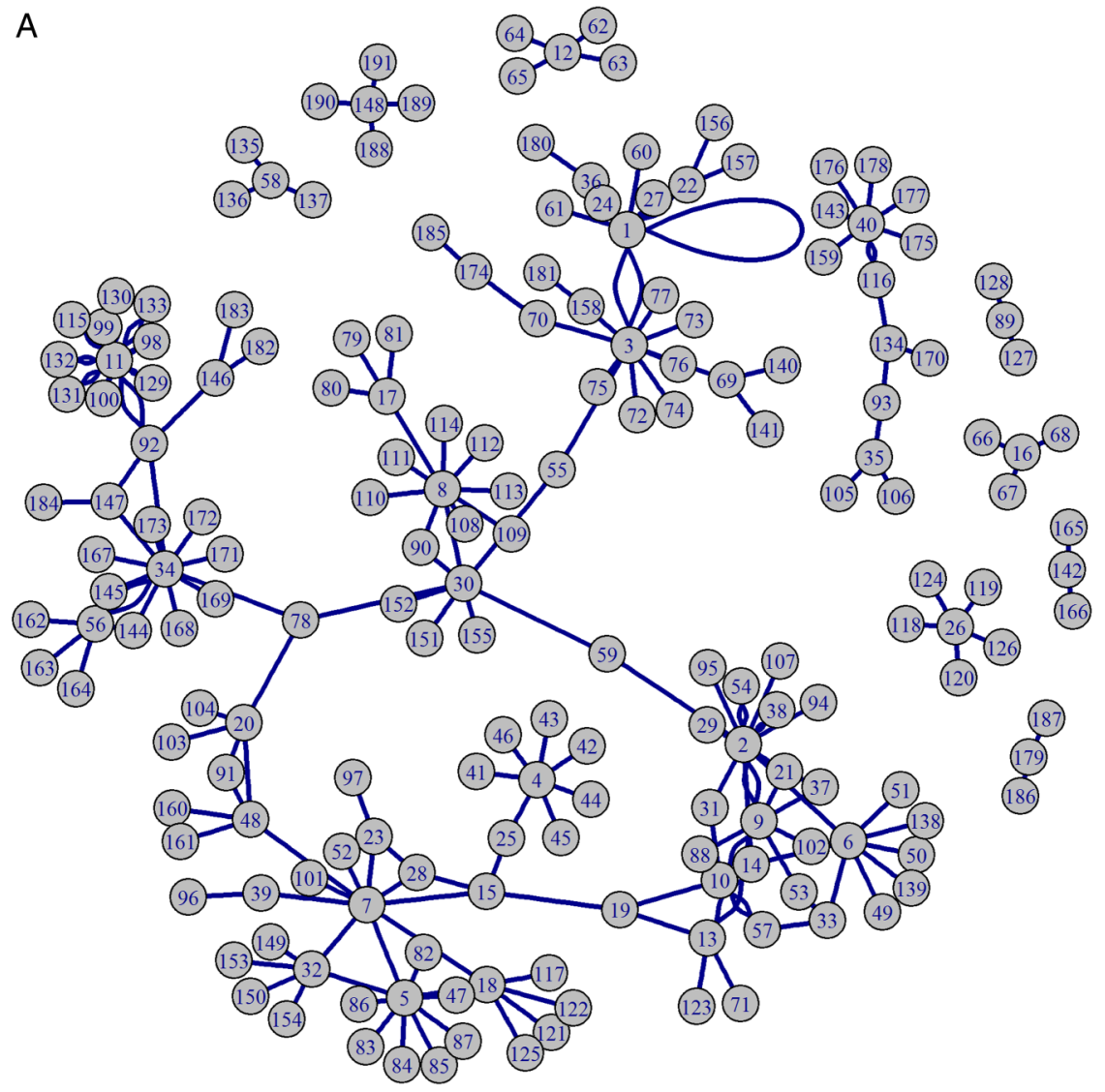

B

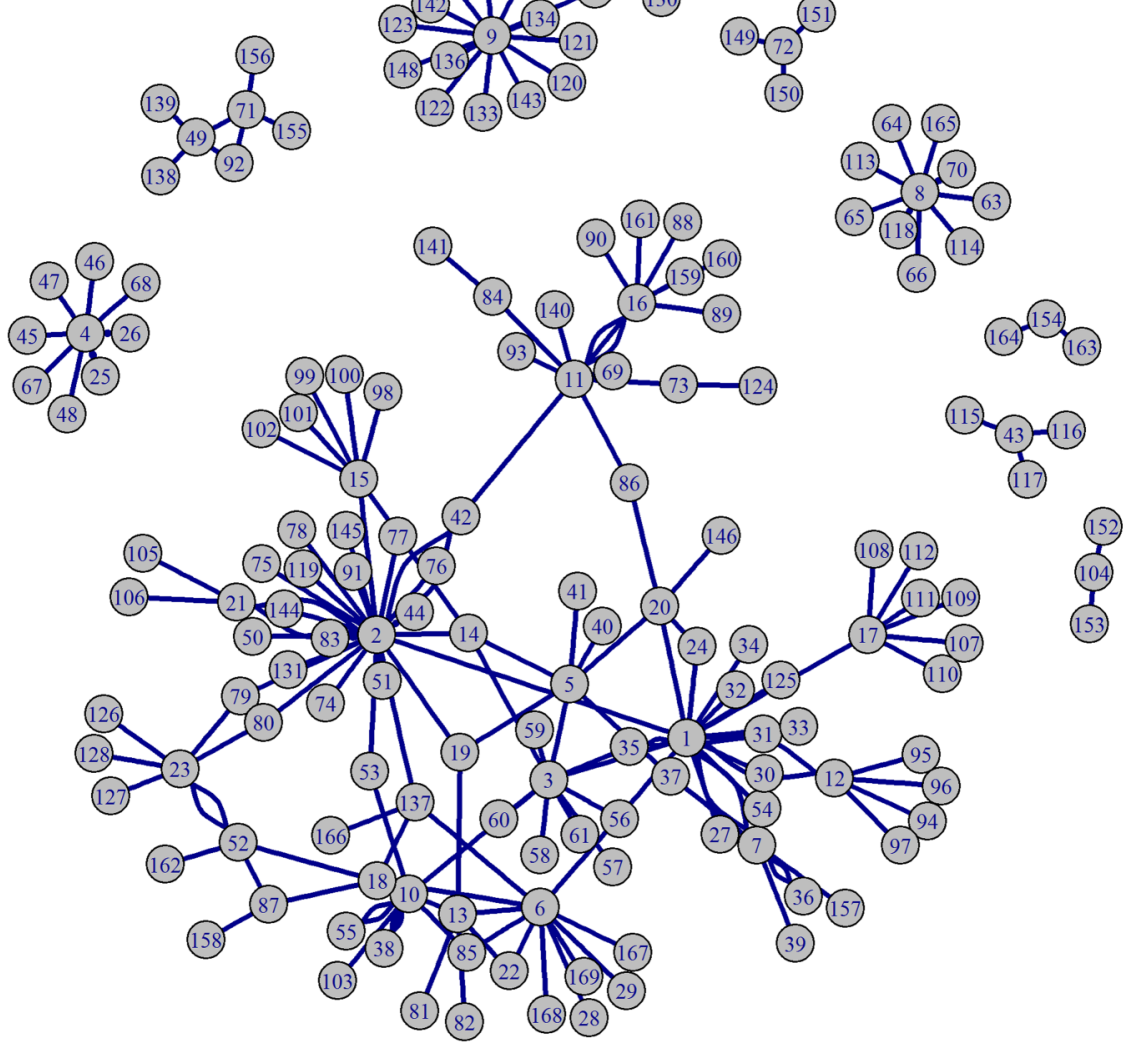


explanation for this pattern is that $\mathrm{CP}$ researchers submit a similar application to both agencies, with researcher's preference to obtain NHMRC funding to build their track records and CPARF picks up the 'fundable but not funded' applications, that is, NHMRC applications deemed worthy of funding but the budget was unavailable. ${ }^{17}$ The distinction between the number of successful NHMRC research proposals that were 'new' versus resubmissions of previously unsuccessful applications could not be determined. ${ }^{21}{ }^{22}$ An alternative explanation is that NHMRC grant review panels may have contained more CP experts in some years compared with others. We examined the NHMRC peer review honour roll to see if we could quantify this for CP experts, but the data definitions were inconsistent. Another explanation is that applicants may not submit in some years because the application process takes an average of $1-2$ months of research time, ${ }^{21}{ }^{22}$ and this could result in the oscillating success patterns especially as the CP community is small and well connected (figure 5). Further, funding success in the previous year may defer applications in the following year as the CP researchers focus on their current projects.

The network analysis highlights the small number of $\mathrm{CP}$ researchers in Australia. The limited number of 'islands' (or silos unconnected to other silos) show most CP researchers are connected through their collaborations; these networks enable research success. ${ }^{4}$ The similar patterns for NHMRC and CPARF networks are due to the majority of CP researchers being in both groups. The CPARF works to expand networks and promote collaborations, for example, hosting the International CP Conference in 2009, and later that year appointing the world's first Professorial Chair of Cerebral Palsy. Hence, there was a peak in CPA funding in 2009, followed by a temporary drop in 2010-2011 as momentum was built for consistent funding. The small community of $\mathrm{CP}$ researchers adapted to being able to obtain CPARF funding and, where possible, CPARF funded what the NHMRC did not fund; both funding bodies were building research momentum for CP.

In the NHMRC funding network, there are relatively successful researchers at the centre of a small network that is not linked to the main community of CP researchers. This is surprising given that these researchers were successful in winning multiple grants. One potential explanation is the relatively common practice among Australian health and medical researchers of deliberately avoiding collaborations in order to have a qualified reviewer available to assess grant applications. The NHMRC uses strict conflict of interest rules, meaning any previous collaborators are unable to review your grant. In a small community of CP researchers, this can mean that grant applications are reviewed by researchers working in other fields who may not be able to recognise the novelty or importance of the proposed research. Another potential explanation is that the unconnected networks indicate researchers from quite different fields of research and expertise which limits collaborations across the CP research community.

These findings are an underestimate of CP funding as the search for grants was based on strict keyword search. CP researchers may have a better chance of being funded by the NHMRC if they use broader terms, such as brain injury or neonatal intensive care, rather than the specific focus on CP. With broader search terms more grants would have been identified as being relevant to $\mathrm{CP}$ research. Interestingly, the findings from this study identified more than double the amount of NHMRC funding as reported by the NHMRC specifically for $\mathrm{CP}^{16}$ This shows the value of looking through the grants summaries in detail rather than only relying on the key words. The identification of only six ARC grants for this analysis may be explained by the specific exclusion of medical and clinical research and focus of ARC funding for disabilities more generally, such as research into social inclusion, community participation and quality of life. Beyond inclusion in this study, other NHMRC grants and many more ARC grants would examine CP within a broader banner of disabilities.

The comparison between Australia and the USA is limited to competitive grants only due to the exclusion of USA philanthropic funding bodies. The analysis was limited to the competitive grants awarded by CPARF for comparison with NHMRC competitive grants. The additional philanthropic funding by CPARF is included in figure 3 as the line 'CPARF Total' to indicate the amount of additional activity funded by CPARF beyond competitive grants. There is overlap in philanthropic funding between countries as CPARF has collaborated on funding projects in the USA through PCORI and the American Academy of Cerebral Palsy and Developmental Medicine, and has initiated funding projects directly in the USA from 2016. The limitation of the analysis extends to the exclusion of other philanthropic or charitable organisations in Australia that contribute funding to people living with CP.

In the context of the economic impact of $\mathrm{CP}$ on the Australian community, of the $\$ 4$ billion spent annually, ${ }^{9}$ the cumulative spend in this study of $\$ 77$ million represents $0.2 \%$ of the economic costs across 10 years. By way of comparison, in 2005 the global spend on cancer research as funded by government and philanthropy was estimated as 14 billion Euros and has resulted in great gains in cancer treatments. ${ }^{3}$ In the USA, the NIH is consistently increasing the funding pattern for CP research. In Australia, the NHMRC needs to provide consistent funding to achieve the research priorities of prevention and cure of CP. Substantial future investment is needed by government and philanthropy to provide significant increased funding for $\mathrm{CP}$ research. A concerted global effort could further decrease the worldwide impact of this lifelong condition on families ${ }^{23}$ however, further research cannot occur without further funding. 
Twitter Follow Adrian Barnett at @aidybarnett

Acknowledgements The authors would like to thank Anisa Rowhani-Farid (QUT) for her assistance with extracting the NHMRC and ARC data from publicly available datasets and reports, and preparing the final report to Cerebral Palsy Alliance Research Foundation that formed the basis for this study. The authors would like to thank Yvonne Wu for her generosity to share her summary on NIH data for inclusion in this study.

Contributors DLH and AGB conceived and designed the study, collated and analysed the descriptive data. AGB analysed the data to compare funding schemes and conduct the network analysis. All authors interpreted the data, drafted the article or revised it critically for important intellectual content and approved the version to be published. DLH is the study chief investigator and guarantor.

Funding This study was funded by the Cerebral Palsy Alliance Research Foundation (PG0115).

Competing interests All authors have completed the ICMJE uniform disclosure form at http://www.icmje.org/coi disclosure.pdf and declare: DLH is a former employee of Cerebral Palsy Alliance. AGB received funding from CPARF for this study, and NHMRC funding for other research. RW and IN are currently employed by Cerebral Palsy Alliance. NB holds the position of Professorial Chair of Cerebral Palsy as financially supported by the CPARF. IN and NB have received NHMRC funding for other research.

Provenance and peer review Not commissioned; externally peer reviewed.

Data sharing statement NHMRC, ARC and NIH data are available from the respective websites. CPARF and full data sets (with some blinding to preserve anonymity) are available from the corresponding author

Open Access This is an Open Access article distributed in accordance with the Creative Commons Attribution Non Commercial (CC BY-NC 4.0) license, which permits others to distribute, remix, adapt, build upon this work noncommercially, and license their derivative works on different terms, provided the original work is properly cited and the use is non-commercial. See: http:// creativecommons.org/licenses/by-nc/4.0/

\section{REFERENCES}

1. Wooding $\mathrm{H}$, Hanney S, Pollitt $\mathrm{A}$, et al. Project Retrosight: understanding the returns from cardiovascular and stroke research: the policy report. Europe: RAND Corporation. 2011. http://www.rand. org/pubs/monographs/MG1079.htm

2. Rottingen JA, Regmi S, Eide M, et al. Mapping of available health research and development data: what's there, what's missing, and what role is there for a global observatory? Lancet 2013;382:1286-307.

3. Eckhouse S, Lewison G, Sullivan R. Trends in the global funding and activity of cancer research. Molec Oncol 2008;2:20-32.

4. Stuss DT. From silos to systems: an integrated approach to neuroscience innovation. Nature Rev Drug Dis 2015;14:295-6.

5. Pinto D, Martin D, Chenhall R. The involvement of patient organisations in rare disease research: a mixed methods study in Australia. Orphanet J Rare Dis 2016;11:2.
6. Christensen D, Van Naarden Braun K, Doernberg NS, et al. Prevalence of cerebral palsy, co-occurring autism spectrum disorders, and motor functioning-Autism and Developmenta Disabilities Monitoring Network, USA, 2008. Dev Med Child Neurol 2014:56:59-65.

7. Smithers-Sheedy H, Mclntyre S, Gibson C, et al. A special supplement: findings from the Australian Cerebral Palsy Register, birth years 1993 to 2006. Dev Med Child Neurol 2016;58(Suppl 2):5-10.

8. Reid SM, Meehan E, Mclntyre S, et al. Temporal trends in cerebral palsy by impairment severity and birth gestation. Dev Med Child Neurol 2016;58(Suppl 2):25-35.

9. Access Economics. The economic impact of cerebral palsy in Australia in 2007. Canberra: Access Economics, 2008. https://www. deloitteaccesseconomics.com.au/uploads/File/The\%20economic\% 20impact\%20of\%20cerebral\%20palsy\%20in\%20Australia\%20in\% 202007.pdf

10. Mclntyre S, Novak I, Cusick A. Consensus research priorities for cerebral palsy: a Delphi survey of consumers, researchers, and clinicians. Dev Med Child Neurol 2010;52:270-5.

11. Novak I, Hines M, Goldsmith S, et al. Clinical prognostic messages from a systematic review on cerebral palsy. Pediatrics 2012;130: e1285-312.

12. Wu YW, Mehravari AS, Numis AL, et al. Cerebral palsy research funding from the National Institutes of Health, 2001 to 2013. Dev Med Child Neurol 2015;57:936-41.

13. Habiby J, Aisen M. More funding, better lives: the case for cerebral palsy research. Dev Med Child Neurol 2015;57: 892-3.

14. McLeod N. Nothing is impossible: adventures in cerebral palsy. Sydney: The Spastic Centre NSW, 2007. https://www. cerebralpalsy.org.au/wp-content/uploads/2013/07/Nothing-isimpossible.pdf

15. Cerebral Palsy Alliance Research Foundation. 10 years of discovery dedicated to prevention, treatment and cure. Sydney: CPA, 2015. https://research.cerebralpalsy.org.au/funding/ annual-reports/

16. National Health and Medical Research Council. NHMRC Research funding 2005-2014: disease and health issues based datasets. Canberra, Australia, 2015. http://www.nhmrc.gov.au/grants-funding/ research-funding-statistics-and-data

17. National Health and Medical Research Council. NHMRC Grants 2000-2014 (Updated July 2015). Canberra, Australia: NHMRC, 2015. http://www.nhmrc.gov.au/grants-funding/research-fundingstatistics-and-data

18. Australian Research Council. Definition of Medical and Dental Research Version 2013.1, 2015. http://www.arc.gov.au

19. Australian Bureau of Statistics. 6401.0-Consumer Price Index Australia, Mar 2016. Canberra: ABS, 2016. http://www.abs.gov.au/ ausstats/abs@.nsf/mf/6401.0

20. Csardi G, Nepusz T. The igraph software package for complex network research. Inter J Complex Syst 2006;1695:1-9.

21. Herbert DL, Barnett AG, Clarke $P$, et al. On the time spent preparing grant proposals: an observational study of Australian researchers. BMJ Open 2013;3:e002800.

22. Barnett AG, Graves N, Clarke P, et al. The impact of a streamlined funding application process on application time: two cross-sectional surveys of Australian researchers. BMJ Open 2015;5:e006912.

23. Richards WB. First Person. Lifestyles Magazine 2016; Pre-Spring:22-26. http://www.lifestylesmagazine.com/website/ magazine.html 